\title{
İnsansız hava aracı ile elde edilen veriler yardımıyla ağaç çıkarımı
}

\author{
Muharrem Cihan Ceylan*1, Murat Uysal1 ${ }^{*}$ \\ ${ }^{1}$ Afyon Kocatepe Üniversitesi Fen Bilimleri Enstitüsü, Harita Mühendisliği, Afyonkarahisar, Türkiye
}

\author{
Anahtar Kelimeler \\ Obje Tabanlı \\ IHA \\ Fotogrametri \\ Sinıflandırma \\ Otomatik Ağaç Tespiti
}

\begin{abstract}
ÖZ
Teknolojik ilerlemeyle birlikte her konuda olduğu gibi haritacılıkta da bilgiye ulaşma konusunda büyük bir aşama kaydedildi. İnsansız hava araçları ile çok sayıda bilgiye hızlı bir şekilde ulaşılan bu dönemde, bu bilgilerin kullanılıp anlamlı verilere dönüştürülmesi konusunda aynı ilerleme gerçekleşmedi. Operatörler yardımıyla anlamlı verilere dönüştürülen bu bilgilerin veri toplamada olduğu gibi hızlı bir şekilde işlenme ihtiyacı doğmuş oldu. Bu çalışmasında, arazi hakkında bilgi edinmede olduğu gibi bu bilgilerin anlamlı verilere dönüşmesi konusunda da doğruluklarına özen göstererek, hızlı bir şekilde anlamlı veriler oluşturma ve bu verilerin çeşitli coğrafi bilgi sistemleri ile entegre edilmesi amaçlanmıştır. Bu çalışmada, RGB(Red-Green-Blue) bantları bulunan iki farklı alanda yapılmıştır. Çalışmada, İHA yardımıyla elde edilen dijital görüntüler, Pix4D yazılımında işlenmiş ve bu dijital görüntülerden ortofoto, sayısal yükseklik modeli ve sayısal arazi modeli elde edilmiştir. Elde edilen bu veriler yardımı ile eCognition yazılımında obje tabanlı sınıflandırma yapılması hedeflenmiştir. Obje tabanlı sınıflandırma yaparken görüntüler segmentasyon işlemi ile anlamlı kümelere ayrıştırılıp, aynı eşik değeri içinde kalan segmentler belirlenen indis değerlerine göre sınıflandırılmıştır. Ardından eCognition yazılımında karşılaştırma amaçlı kontrol verisi üretilip, hata matrisi kullanılarak doğruluk analizi yapılmıștır.
\end{abstract}

\section{Tree detection from data obtained by unmanned aerial vehicle}

\author{
Keywords \\ Object-Base \\ UAV \\ Photogrammetry \\ Classification \\ Automatic Tree; Detection
}

\begin{abstract}
With the technological advancement, a great progress has been made in reaching sales in cartography as well as in its depth. This article, which was quickly reached by unmanned aerial vehicles and numerous vehicle vehicles, did not make the same progress in converting these copies. In this process, which helps the operators to realize, a need for fast processing, such as collection, was born. In this study, it was aimed to create meaningful data quickly and integrate this study with various geographic information systems, taking care of their accuracy in converting these important meaningful data as in obtaining information about the land. These sources were made in two different areas with RGB (Red-Green-Blue) bands. In the study, digital images obtained from UAVs were processed in Pix4D software and orthophoto, digital elevation model and digital terrain model were obtained from these digital images. With the help of these data obtained, it is aimed to make object-oriented in eCognition software. When making object-based classification, images are separated into meaningful clusters with segmentation process, and segments within the same threshold value are classified according to their values. Then, control data for comparison was generated in the eCognition software and the error matrix was analyzed in image analysis.
\end{abstract}




\section{GíRiş}

Günümüzde haritacılı alanında geleneksel yöntemler ve fotogrametrik yöntemler olarak veriye ulaşmak oldukça kolaylaştı (Yakar ve Doğan, 2018; Yiğit vd., 2020). Yeryüzü veya yeryüzünün üstünde var olan doğal-yapay nesnelerin türevleri ile ilgili bir hayli bilgi mevcut (Taşdemir vd., 2009; Ulukavak vd., 2019; Alptekin vd., 2019a; Hamal vd., 2020). Ancak bu bilgilerin işlenip, anlamlı veriler oluşturma noktasında bilgi edinmede olduğu kadar ivedilik söz konusu değil. Bilgilerin otomatik olarak anlaml veriler olarak işlenmesi, sınıflandırılması projelerde zaman ve maliyet noktalarında ciddi azalmalara vesile olabilir (Yilmaz vd., 2012; Şenol vd., 2017; Alptekin vd., 2019b; 2020; Sarı vd., 2020; Kaya vd., 2021).

Yapılan literatür araştırması sonucunda nesne tabanlı ve piksek tabanlı olmak üzere iki ana sinıflandırma yönteminin olduğu ve nesne tabanl sınıflandırma yönteminin, piksel tabanlı sınıflandırma yöntemine göre daha doğru sonuçlar verdiği görülmüştür (Yiğit ve Uysal, 2020). Nesne tabanlı sinıflandırma yönteminin piksel tabanlı sınıflandırma yöntemine göre daha daha doğru sonuçlar vermesinin nedeni; verideki komşuluk, doygunluk, renk vb. değerleri ișleyerek emsal kapsamdaki pikselleri kümelendirmesinden dolayıdır (Kaya ve Polat, 2020; Ulvi ve Toprak, 2016)). Bu piksellerin kümelendirilmesi sonrasında haritadaki nesnelere ait anlamlı biçimler meydana gelmektedir. Bu biçimleri meydana getirme yani segmantasyon işlemi, nesne tabanlı sınıflandırma yönteminin en mühim aşamasıdır (Yiğit ve Kaya, 2020; Polat vd., 2020). Zira sinıflandırmaya tabii tutulacak veriler oluşturduğumuz segmentler yardımıyla belirlenmektedir. Segmentasyonun doğru yapılabilmesi içinse; ölçek, şekil ve yoğunluk parametrelerinin değerlerini, dijital görüntü için en elverişli olacak şekilde değerler seçilerek kullanmak gereklidir (Şenol vd., 2020; Ulvi, 2020; Polat ve Kaya, 2021). Bu değerler, Her çalışma alanı için ayrı ayrı seçilmelidirler.

$\mathrm{Bu}$ çalışmada Red-Green-Blue değerlerine sahip bantların bulunduğu dijital görüntüler kullanılarak ortofoto üretilmiştir. Ve bu ortofoto kullanılarak ağaçlık alanların tespiti uygulamalı bir şekilde araştırılmıştır.

\section{2. ÇALIŞMA ALANI VE VERİ TOPLAMA YÖNTEMİ}

Bu çalışmada Manisa ili sınırları içinde DJI Phantom 4 Pro cihaz ile çekilmiş 217 adet RGB bantlı dijital görüntü bulunmaktadır. Bu dijital görüntüler, 100 metre yükseklikten $\% 80$ bindirmeli olarak çekilmiş olup, üretilen ortofotonun yer örnekleme aralığl 2,68 cm çözünürlüğe sahiptir. 9 adet yer kontrol noktası kullanılmıştır (Şekil 1).

Diğer test alanı ise Bangkok, Tayland'da bulunan Thammasat Üniversitesi kampüsüdür. SenseFly’ın sitesinden temin edilen SenseFly eBee X cihazı ile çekilmiş 443 adet RGB bantlı dijital görüntü kullanılmıștır. $\mathrm{Bu}$ dijital görüntüler 215 metre yükseklikten bindirmeli olarak çekilmiş olup, üretilen ortofotonun yer örnekleme aralığı $6,04 \mathrm{~cm}$ çözünürlüğe sahiptir (Şekil 2).

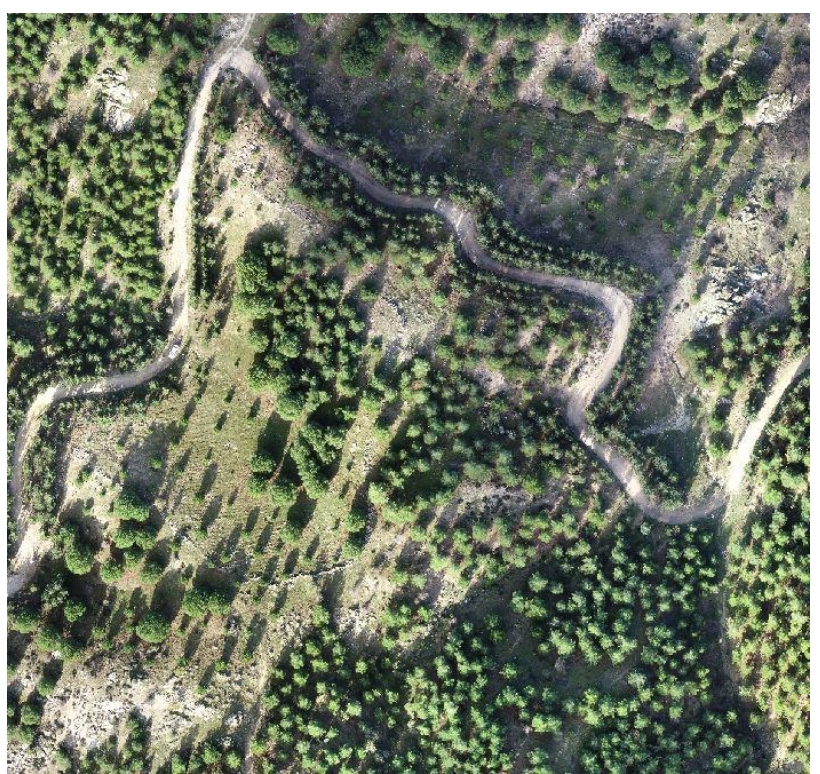

Şekil 1. Test Alanı 1

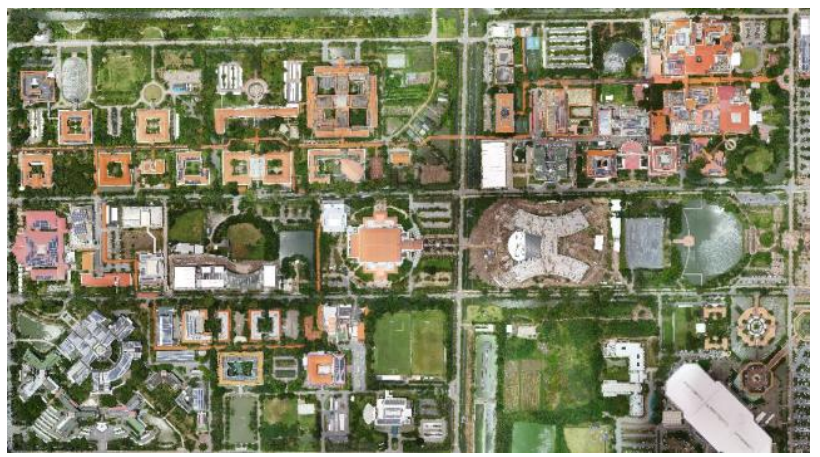

Şekil 2. Test Alanı 2

\section{YÖNTEM}

Yapılan çalışmanın iş akış şeması Şekil 3'de gösterildiği gibidir;
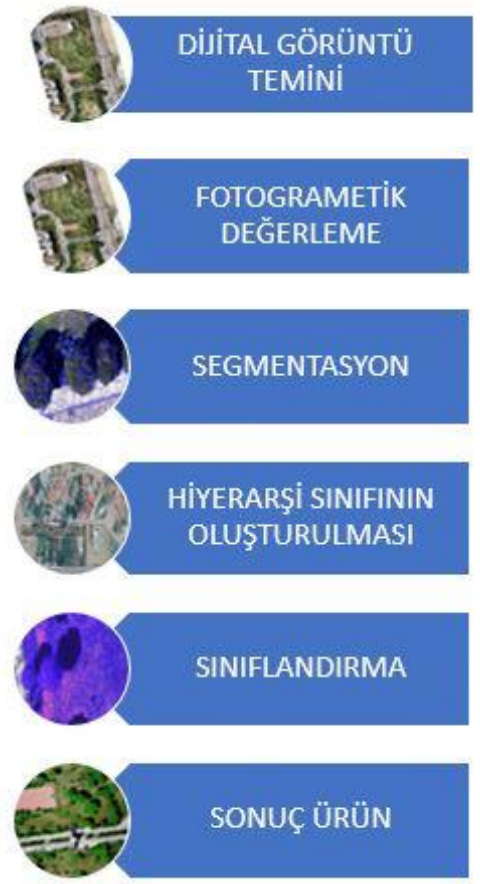

Şekil 3. İş Akış Şeması 


\subsection{Fotogrametrik Değerlendirme}

$\mathrm{Bu}$ aşamada Pix4D yazılımı kullanılarak dijital görüntülerin fotogrametrik değerleme işlemi yapılmıştır. Test Alanı 1 için toplamda 9 adet yer kontrol noktası tesis edilmiş olup bu noktalar birer saat arayla GNSS alıcısı ile 10 epoklu ölçülmüştür. Bu YKN'lerin fotogrametrik değerleme sonrası oluşan hata değerleri Şekil 4'de verilmiștir. Test Alanı 2 de YKN kullanılmamıștır. Dijital Görüntüler kullanılarak Pix4D yazılımı yardımı ile ortofoto, Sayısal arazi modeli ve Sayısal Yükseklik Modeli üretildikten sonra segmentasyon aşamasına geçilmiştir.

\begin{tabular}{|c|c|c|c|c|c|c|}
\hline \multirow[b]{3}{*}{ N.N } & \multicolumn{6}{|c|}{ Fotogrametrik Değerleme Sonucu Elde Edilen Koordinat Hata Değerleri } \\
\hline & \multicolumn{3}{|c|}{ ViFarklar(cm) } & \multicolumn{3}{|c|}{$\operatorname{ViViFarklar}\left(\mathrm{cm}^{2}\right)$} \\
\hline & $v_{x}$ & $\mathbf{v}_{y}$ & $\mathrm{v}_{2}$ & $v_{x} v_{x}$ & $\mathrm{v}_{y} \mathrm{v}_{y}$ & $\mathrm{~V}_{2} \mathrm{~V}_{2}$ \\
\hline YKN1 & 1.5 & 1.1 & 2.5 & 2.25 & 1.21 & 6.25 \\
\hline $\mathrm{YKN} 2$ & 1.7 & 1.3 & 2.9 & 2.89 & 1.69 & 8.41 \\
\hline YKN3 & 2.1 & 1.9 & 3.1 & 4.41 & 3.61 & 9.61 \\
\hline $\mathrm{YKN} 4$ & 2.5 & 2 & 3.6 & 6.25 & 4 & 12.96 \\
\hline YKN5 & 2.2 & 1 & 2.3 & 4.84 & 1 & 5.29 \\
\hline YKN6 & 1.8 & 2 & 2.1 & 3.24 & 4 & 4.41 \\
\hline YKN7 & 0.8 & 0.3 & 1.9 & 0.64 & 0.09 & 3.61 \\
\hline YKN8 & 1.6 & 2.2 & 3 & 2.56 & 4.84 & 9 \\
\hline \begin{tabular}{|l|} 
YKN9 \\
\end{tabular} & 2.8 & 0.3 & 3 & 7.84 & 0.09 & 9 \\
\hline
\end{tabular}

Şekil 4. YKN Hata Değerleri

\subsection{Segmentasyon ve Sinıflandırma}

Nesne tabanlı sınıflandırma metodunu piksel tabanlı sınıflandırma metoduna göre daha doğru kılan en önemli faktör, piksel tabanlı gruplandırmada piksellerin teker teker değerlendirilmesine karşın, nesne tabanlı gruplandırmada bütün pikselleri tek bir nesne gibi değerlendirip, anlamlı segmentler oluşturmasıdır. eCognition Developer yazılımı kullanılarak bu segmentasyon yöntemi yapılmaktadır. Fotogrametrik değerleme neticesinde üretilen ortofoto, sayısal arazi modeli ve sayısal yükseklik modelini kullanarak segmentasyon işlemi yapılmaktadır. Segmentasyonun ana mantığı, benzer değerlere sahip pikselleri gruplandırıp çalışma alanına ait görüntü objeleri oluşturmaktır. (Yiğit ve Uysal, 2019; Kaya ve Polat, 2021)

Segmentasyon işlemi, yukarıdan-aşağıya (topdown) ve aşağıdan-yukarıya (bottom-up) olmak üzere iki farklı yöntem olarak işlemektedir (Definiens, 2012; Şenol ve Kaya, 2019).

Yukarıdan aşağıya metodun dayanağında dijital görüntünün tamamının en ufak parçalara ayrıștırılması işlemi vardır. Yukarıdan aşağıya segmentasyon metodunun 3 farklı temel metodu vardır. Bunlar; chessboard segmentation, quadtree-based segmentation ve contrast split segmentation algoritmalarıdır. Segmentasyon işleminin ikinci stratejisi aşağıdan yukarıya bölümlemedir. Bu yaklaşımda, küçük parçalar belirli bazı kriterler göz önüne alınarak büyük parçalar olarak elde edilmektedir (Yiğit ve Uysal, 2020).

Bu uygulama çalışmasında iki test alanı için de çoklu çözünürlüklü segmentasyon yöntemini kullanılmıştır. Çoklu çözünürlüklü segmentasyonda kullanıcı ölçek(scale), şekil (shape), yoğunluk (compactness) değerlerini kendisi tanımlar. Bu şekilde yeryüzündeki nesleleri vektörel olarak oluşturmak için dijital görüntü parçalara ayrılmış olur. Girilen bu değerlerden şekil ve yoğunluk parametreleri birbirlerini 1 'e tamamlar. Segmentlerin oluşumunda en önemli değer ise ölçek parametresidir. Uygulama çalışmalarda ölçek, şekil ve yoğunluk parametreleri farklı değerler için denenmiştir ve son olarak her çalışma alanı için ayrı ayrı en uygun değer kullanılmaktadır. Şekil parametresi 0.3 , yoğunluk parametresi 0.7 alınarak farklı değerlerde ölçek parametresi karşılaștırmasını șekil 5 ve șekil 6'da görebilirsiniz.
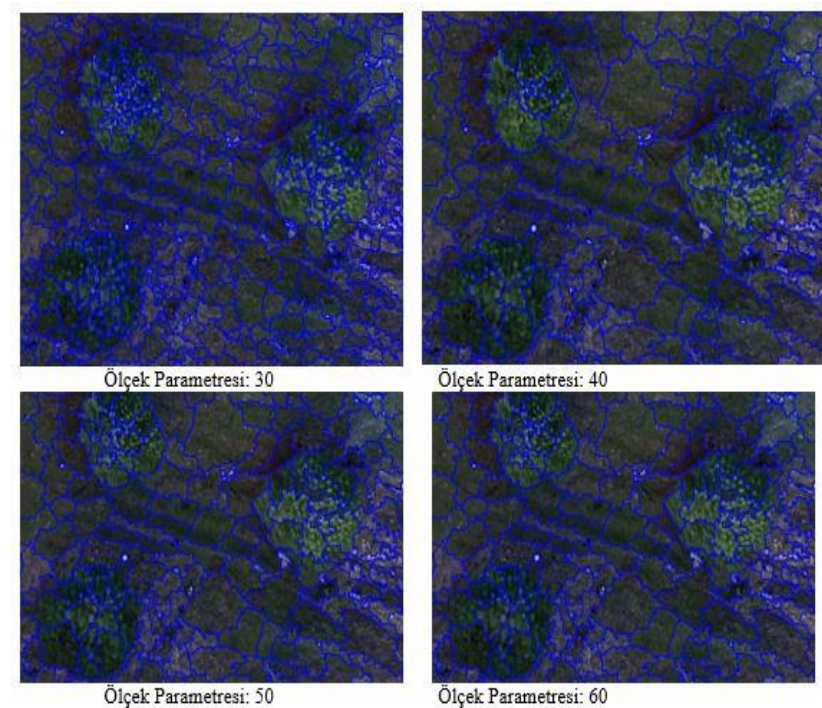

Şekil 5. Test Alanı 1 için Ölçek Parametresi Karşılaştırması.
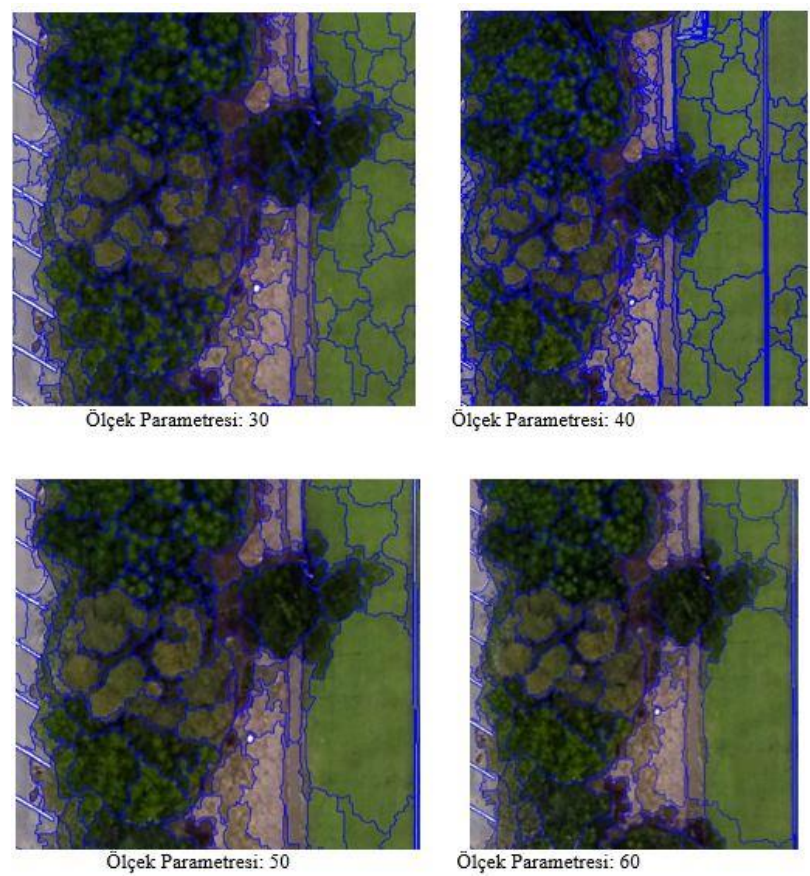

Şekil 6. Test Alanı 2 için Ölçek Parametresi Karşılaştırması.

Segmentasyon işlemini tamamladıktan sonra sınıflandırma işlemine geçilir.

Çalışmada, sınıflandırma işlemini yaparken kullandığımız 3 ayrı parametre vardır. Ecognition yazılımında Create new Arithmetic Feature (Yeni aritmetik özellik oluştur) komutu kullanılarak normalize edilmiş sayılsal arazi modelini oluştururuz. Bu değerleri kullanarak yer yüzü segmentlerini ve yerüstünde 
bulunan nesneleri barındıran segmentleri ayırmak hedeflenmiștir. Yeryüzü üstünde bulunan segmentleri ayırdıktan sonra literatür taraması sonucu elde ettiğimiz indisler (Șekil 7) arasından GLI, YBO indislerini kullanarak ağaçlık alanları diğer yeryüzünün üstünde bulunan nesnelerden ayırmış oluruz (Şekil 8). Ardından Merge komutu ile aynı sınıfa atanmış komşu segmentleri birleștiririz.

\begin{tabular}{|c|c|}
\hline Bant İndisi & Formül \\
\hline \multirow[t]{2}{*}{ Ortalama Bantlar Oranı (OBO) } & Kirmuz + Mavi + Yeşil \\
\hline & 3 \\
\hline Kirmzı Yeșil Bant Farkl (K-Y) & Kırmızı - Yeșil \\
\hline Excess Green Index (EGI) & (2x Yeşil) - Mavi-Kirmızı \\
\hline Yeşil Yaprak İndeksi (GLI) & (2x Yeşil) + Mavi + Kirmızı \\
\hline Ücgensel Yeşillik Indeksi (TGI) & Yeșil - $(0.39 \mathrm{x}$ Kirmizz $-0.69 \mathrm{x}$ Mavi $)$ \\
\hline \multirow[t]{2}{*}{ Yeşil Bant Oranı (YBO) } & Yeşil \\
\hline & Mavi + Kirmuzl + Yeșil \\
\hline \multirow[t]{2}{*}{ Mavi Bant Oranı (MBO) } & Mavi \\
\hline & Mavi + Krrmuza + Yeșil \\
\hline \multirow{2}{*}{$\begin{array}{l}\text { Normalize Edilmiş Akuatik Bitki Endeksi } \\
\text { (NRAVI) }\end{array}$} & Yeșil-Kirmizl \\
\hline & $\overline{\text { Yeșil + Kırmuzl }}$ \\
\hline \multirow{2}{*}{$\begin{array}{l}\text { Görünür Bölge Atmosferik Dayankllillk } \\
\text { Indeksi (VARI) }\end{array}$} & Yeșil-Kurmizl \\
\hline & Mavi + Yeşil + Krrmızı \\
\hline Excess Red Vegetation Index (ER) & (1.4x Kirmızı) - Yeșil \\
\hline
\end{tabular}

Şekil 7. Kullanılan İndisler
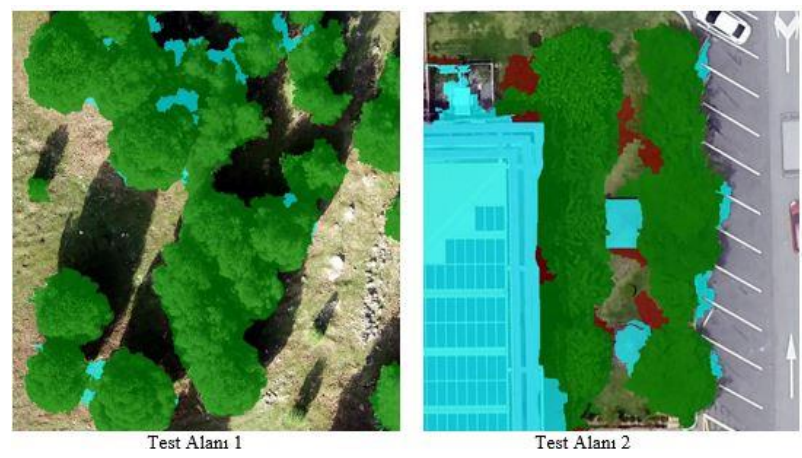

Şekil 8. Test Alanlarının Sınıflandırma Görüntüsü

Ecognition yazılımında sınıflandırma için yapılan ișlem adımları Şekil 9 ve Şekil 10'da sınıflandırma sonuçları Şekil 11'de verilmiştir.

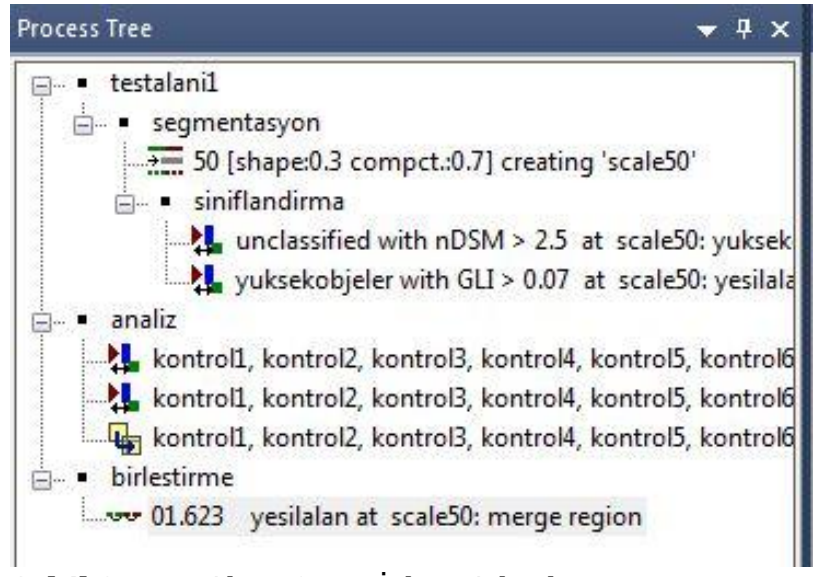

Şekil 9. Test Alanı 1 için İşlem Adımları

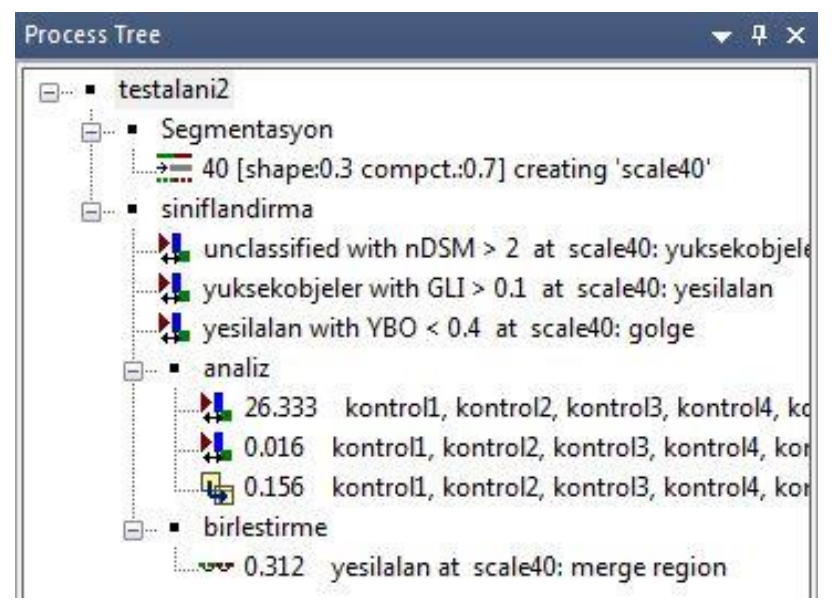

Şekil 10. Test Alanı 2 için İșlem Adımları
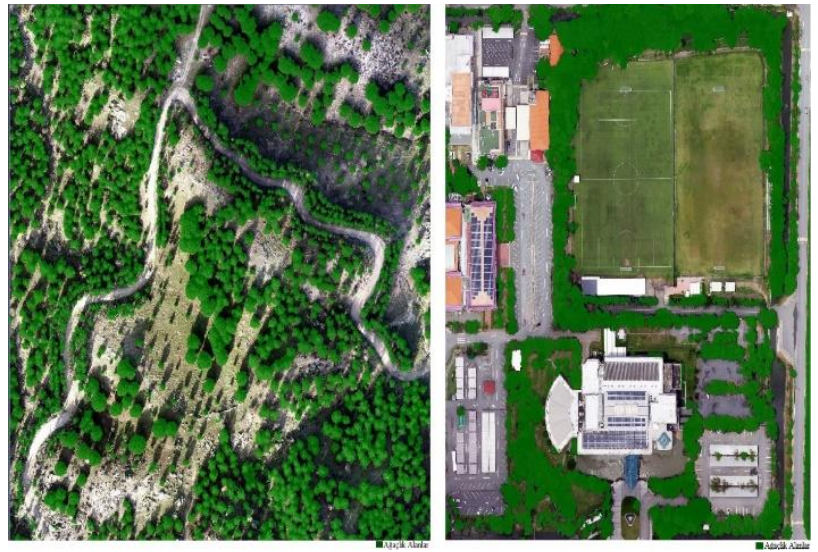

Şekil 11. Test Alanı 1 ve 2 için Sınıflandırma Sonuçları

\section{BULGULAR}

Doğruluk analizi, sınıflandırma sonucu oluşan sınıf verilerinin referans olarak kabul edilen veriler ile istatistiksel olarak karşılaştırılmasını esas alan bir doğruluk kontrol etme şeklidir. Yapılan bu istatistiksel analizler sonucunda elde edilen hata matrisi ile sınıflandırma sonucunun sağlıklı olup olmadığı anlaşılmaktadır. Hata matrisi, 0 ile 1 arasında değişiklik gösteren kappa katsayısı ile istatistiksel olarak analiz edilir.

\subsection{Fotogrametrik Değerlendirme}

Yapılan sınıflandırmanın doğruluk oranını hesaplamak için eCognition Developer yazılımının hata matrisi ile yaptığı doğruluk değerlendirmesi kullanılmıştır. Çalışmada Destek vektör makineleri ve karar ağaçlarının matematiksel modelini kullanarak eğitim verisi üretilmiştir. Kullanılan parametreler Şekil 12 'de gösterilmiştir.

Yazılımda ağaç sınıfında bulunan segmentlerden on adeti ayrı ayrı kontrol1, kontrol2, kontrol3, kontrol4, kontrol5, kontrol6, kontrol7, kontrol8, kontrol9 ve kontrol10 sınıfına manuel olarak atanmıștır. Literatürde kontrol sınıfı için kullanılan sayı beş ile on arasında değişmektedir. Atanmış sınıflardan sonra "classifier" komutu ile kontrol sınıfındaki segmentler test alanı 1 için normalize edilmiş sayısal arazi modeli ve yeșil yaprak indeksi, test alanı 2 için ekstra olarak yeşil bant oranı değerlerine göre makine öğrenmesine tabii tutulup bir 
kontrol verisi üretilmiştir. Üretilen bu veri yine "classifier" komut ile "apply" seçeneği seçilerek her sinıfa uygulanmıștır. Daha sonra "classified image objects to samples" komutu ile bu sinıflar örneklem kategorisine atanmıştır.

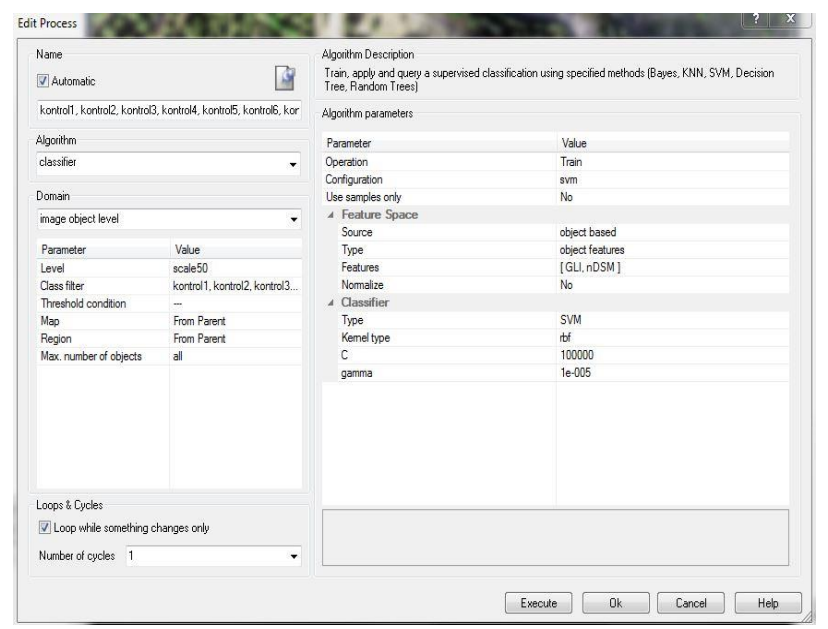

Şekil 12. Destek Vektör Makineleri ile Üretilen Kontrol Verisi Parametreleri

\subsection{Hata Matrisi ile Doğruluk Analizi}

Karıșıklık matrisi olarak da isimlendirilen hata matrisi, test verisi kategorisindeki model ile doğruluk analizi yapmak için sıkça kullanılan bir yöntemdir. $\mathrm{Bu}$ matristen doğruluğu şu şekilde öğrenebiliriz; iki olası görülen sınıf vardır. Bunlar evet ve hayırdır. Örneğin, bir çalışma sahasında ağaçlık alanların varlığını tahmin ediyor olsaydık, "evet", yani çalışma sahasında ağaçlık alanların var olduğu anlamına gelirdi ve "hayır" çalışma sahasında ağaçlık alanların var olmadığı anlamına gelirdi. Bu sinıflar üzerinden hata matrisi ile ilgili en temel terimleri tanımlayacak olursak,

○ Doğru Pozitifler (TP): "Evet" gerçekte ağaçlık alanlardır ve bizim de ağaçlık alan olarak tahmin ettiğimiz durumlardır.

- Doğru Negatifler (TN): "Hayır" gerçekte ağaçlık olmayan alanlardır ve bizim de ağaçlık olmayan alan olarak tahmin ettiğimiz durumlardır.

- Yanlış Pozitifler (FP): "Evet"i tahmin ettik yani ağaçlık alan olarak öngördük fakat gerçekte ağaçlık olmayan alanlardır.

- Yanlış Negatifler (FN): "Hayır"ı tahmin ettik yani ağaçlık olmayan alan olarak öngördük fakat gerçekte ağaçlık olan alanlardır.

Hata matrisi ile doğruluk analizi yaparken, sınıflandırma ile doğruluk analizi arasındaki uyumu ölçmek için Kappa katsayısı kullanılır. Yazılımda "Global Kappa Index of Agreement" olarak geçen bu katsayısı;

$$
K=\frac{N \sum_{i=1}^{n} m_{i, i}-\sum_{i=1}^{n}\left(G_{i} G_{i}\right)}{N^{2}-\sum_{i=1}^{n}\left(G_{i} G_{i}\right)}
$$

Şeklinde tanımlanır.

Formülde kullanılan değerler hakkında bilgi verecek olursak;

i: sınıf numarasıdır

$\mathrm{N}$ : doğruluk değerlerine kıyasla toplam sınıflandırılmış değer sayısıdır

mi,i : sınıf i olarak da sınıflandırılan doğruluk sınıf i'ye ait değerlerin sayısıdır (yani, karışıklık matrisinin diyagonalinde bulunan değerler)

$\mathrm{Ci}$ : i Sınıfa ait tahmini toplam değer sayısıdır

Gi : i sınıfına ait toplam doğruluk değeri sayısıdır.

Ecognition Developer yazılımında araçlar sekmesinden "accuracy assessment" komutunu kullanarak, istatistik türü olarak da "Error Matrix Based on Samples (Örneklere Dayalı Hata Matrisi)" seçilmiştir. Yazılımdaki örnek seçim ekranı Şekil 13'de gösterilmiştir.

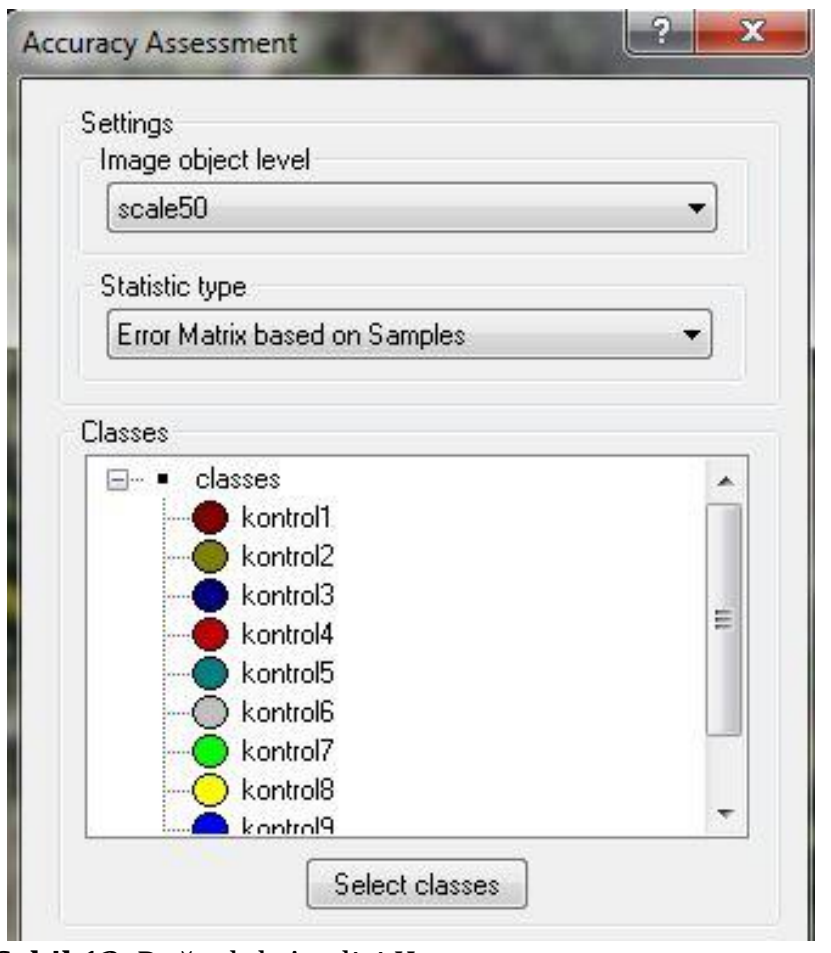

Şekil 13. Doğruluk Analizi Komutu.

Test alanı 1 için oluşan doğruluk değerlendirmesi tablosu Şekil 14'de verilmiștir, test alanı 2 için oluşan doğruluk değerlendirmesi tablosu Şekil 15'de verilmiştir.

\begin{tabular}{|c|c|c|c|c|c|c|c|c|c|c|c|c|c|}
\hline User Class $\}$ & kontroll & kontrol2 & kontrol & & atrol4 & kontrol5 & kontrol6 & kontrol? & 17 kontroll & is kontrols & & ontrol10 Sum & \\
\hline kontroll & & 92 & 2 & 2 & 1 & & 5 & 3 & 5 & 2 & 6 & 2 & 120 \\
\hline kontrol2 & & 0 & 32 & 0 & 0 & 0 & 0 & 0 & 5 & 0 & 0 & 0 & 37 \\
\hline kontrol3 & & 2 & 2 & 78 & 8 & 8 & 7 & 0 & 0 & 4 & 2 & 1 & 104 \\
\hline kontrol4 & & 0 & 0 & 5 & 53 & & 0 & 3 & 0 & 0 & 0 & 0 & 61 \\
\hline kontrol.5 & & 0 & 1 & 2 & 0 & & 87 & 8 & 4 & 0 & 0 & 0 & 102 \\
\hline kontrol6 & & 0 & 0 & 0 & 0 & & 0 & 41 & 0 & 0 & 0 & 6 & 47 \\
\hline kontrol7 & & 0 & 4 & 0 & 0 & & 0 & 0 & 89 & 8 & 0 & 1 & 102 \\
\hline kontrols & & 0 & 0 & 4 & 0 & & 0 & 0 & 0 & 91 & 0 & 2 & 97 \\
\hline kontrol9 & & 0 & 0 & 5 & 0 & & 0 & 0 & 0 & 0 & 78 & 0 & 83 \\
\hline kontrol10 & & 0 & 0 & 0 & 0 & & 0 & 0 & 3 & 0 & 0 & 86 & 89 \\
\hline unclassified & & 0 & 0 & 0 & 0 & & 0 & 0 & 0 & 0 & 0 & 0 & 0 \\
\hline Sum & & 94 & 41 & 96 & 62 & & 99 & 55 & 106 & 105 & 86 & 98 & \\
\hline Prodver & 0.978 & 0.78 & 1805 & 0.8125 & 0.8548 & 0.878 & 0.7 & 455 & 8396 & .8667 & 0.907 & 0.87755 & \\
\hline User & 0.766 & $667 \quad 0.86$ & & 0.75 & 0.8689 & 0.852 & 0.87 & 723 & 8726 & 9381 & 0.94 & 0.96629 & \\
\hline Overall Acor & 0.863 & & & & & & & & & & & & \\
\hline KIA & 0.791 & 916 & & & & & & & & & & & \\
\hline
\end{tabular}

Şekil 14. Test Alanı 1 için Oluşan Doğruluk Analizi. 


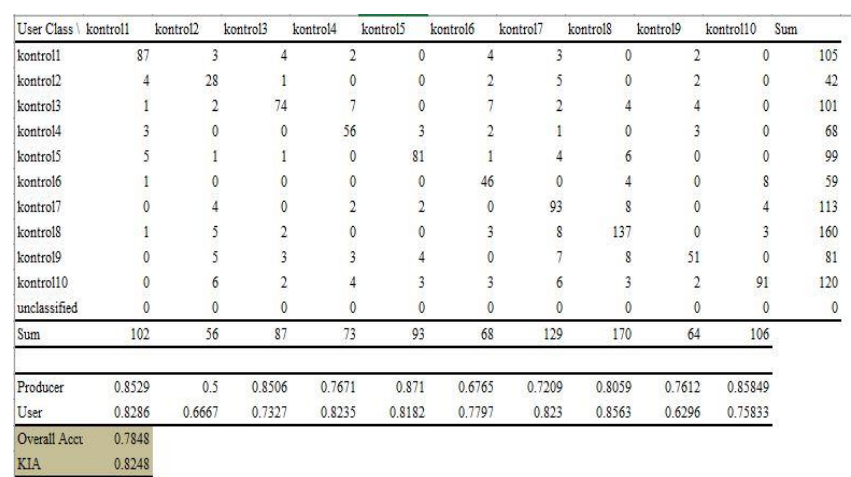

Şekil 15. Test Alanı 2 için Oluşan Doğruluk Analizi

Oluşan bu hata matrisi sonucu test alanı 1 için;

Genel doğruluk $=0.8634=\% 86$

Genel KIA $=0.7916=\% 79$

Olarak hesaplanmıştır.

Oluşan bu hata matrisi sonucu test alanı 2 için;

Genel doğruluk $=0.7848=\% 79$

Genel KIA $=0.8248=\% 83$

Olarak hesaplanmıştır.

\section{SONUCLAR}

Yapılan bu çalışma sonrası șu sonuçlara varılmıștır;

Segmentasyon işlemi, bilgiyi anlamlı verilere dönüștürme konusunda kullanıcıyı oldukça rahatlatan bir işlem olmakla birlikte, segmentasyonun çeșitleri arasından en doğru sonuca çok çözünürlüklü segmentasyon yöntemi ile ulaşıldığı görülmüștür.

Nesne tabanlı sinıflandırmanın, geleneksel bir metod olan piksel tabanlı sınıflandırmaya göre veriyi daha hızlı işleyip, daha doğru sonuçlar vermektedir. Kullanılan parametreler ve değerler her çalışma alanı için farklı seçilip, farklı sonuçlar verebilmektedir.

$\mathrm{Bu}$ çalışmada uygulanan yöntem ile sık ağaçlık alanların olduğu alanlarda yani ormanlık alanlarda da ağaçlık alanların tespitinin başarılı bir şekilde gerçekleştiği görülmüştür.

\section{ARAŞTIRMACILARIN KATKI ORANI}

Yazarlar bu araştırma makalesine eşit katkı sunmuşlardır.

\section{ÇATIŞMA BEYANI}

Yazarlar arasında herhangi bir çıkar çatışması bulunmamaktadır.

\section{KAYNAKÇA}

Alptekin A \& Yakar M (2020). Mersin Akyar Falezi'nin 3B modeli. Türkiye Lidar Dergisi, 2(1), 5-9.

Alptekin A, Çelik M Ö, Doğan Y \& Yakar M (2019a). Mapping of a rockfall site with an unmanned aerial vehicle. Mersin Photogrammetry Journal, 1(1), 1216.

Alptekin A, Çelik M Ö, Kuşak L, Ünel F B \& Yakar M (2019b). Anafi Parrot'un Heyelan Bölgesi Haritalandırılmasında Kullanımı. Türkiye İnsansız Hava Araçları Dergisi, 1(1), 33-37.
Baatz M \& Schape A (2000). Multi resolution segmentation: an optimization approach for high quality multi scale image segmentation, Proceedings of Twelfth Angewandte Geographische Informations verarbeitung, Wichmann-Verlag, Heidelberg, 12-23.

Benz U C, Hofmann P, Willhauck G, Lingenfelder I, Heynen M., (2004), Multi-resolution object-oriented fuzzy analysis of remote sensing data for GIS- ready information, ISPRS Journal of Photogramemetry and Remote Sensing, 58 (3-4), 239-258

Boyacı D (2012). Cbs-Uzaktan Algilama entegrasyonu ve örnek uygulama: uydu görüntülerinden detay ve otomatik öznitelik tespiti, Doktora Tezi, Selçuk Üniversitesi Harita Mühendisliği Anabilim Dalı, Konya.

Çölkesen İ (2009). Uzaktan Alglamada İleri Sinıflandırma Tekniklerinin Karşılaştırılması ve Analizi, Y. Lisans Tezi, Gebze Teknik Üniversitesi, Gebze Yüksek Teknoloji Entitüsü, 153s, Gebze.

Çölkesen İ, Yomralığlu T \& Kavzoğlu T. (2015). Obje Tabanlı Sinıflandırmada Bölgeleme Esasına Dayalı Ölçek Parametresi Tespiti: Worldview-2 Uydu Görüntüsü Örneği, Harita Dergisi, 154, 9-18.

Definiens (2012). Definiens Developer XD 2.0.4. Reference Book, Definiens AG, München, Germany,

Ghamisi P, Plaza J, Chen Y, Li J \& Plaza A J (2017). Advanced Spectral Classifiers for Hyperspectral İmages: A Review, IEEE Geoscience and Remote Sensing Magazine, 5, 8-32.

Hamal S N G, Sarı B \& Ulvi A (2020). Using of Hybrid Data Acquisition Techniques for Cultural Heritage A Case Study of Pompeiopolis. Türkiye Insansız Hava Araçları Dergisi, 2(2), 55-60

Hofmann P (2001), "Detecting Urban Features From IKONOS Data Using an Object-Oriented Approach, First Annual Conference of the Remote Sensing \& Photogrammetry Society 12-14 September 2001, 2833.

Kamps M, Bouten W \& Seijmonsbergen A (2017). Lidar and Orthophoto Synergy to Optimize Object-Based Landscape Change: Analysis Of An Active Landslide, Remote Sensing, 9, 805.

Kaya Y \& Polat N (2020). Investigation Of Phenological Stages of Wheat Plant Using Vegetation Index. Mersin Photogrammetry Journal, 2(1), 24-28.

Kaya Y \& Polat N (2021) Bitki İndeksleri Kullanarak Buğday Bitkisinin Rekolte Tahmini. Dicle Üniversitesi Mühendislik Fakültesi Mühendislik Dergisi, 12(1), 99110. DOI: https://doi.org/10.24012/dumf.860325

Kaya Y, Yiğit A Y, Ulvi A \& Yakar M (2021). Arkeolojik Alanların Dokümantasyonununda Fotogrametrik Tekniklerinin Doğruluklarının Karşılaştırmalı Analizi: Konya Yunuslar Örneği. Harita Dergisi, 165, 57-72.

Korsgaard N J, Nuth C, Khan S A, Kjeldsen K K, Bjørk A A, Schomacker A \& Kjær K H (2016). Digital Elevation Model and Orthophotographs of Greenland Based on Aerial Photographs From 1978-1987, Scientific Data, 3, 160032.

Polat N \& Kaya Y (2021) Çok Bantlı Uydu Görüntüleriyle Orman Yangınlarının Belirlenmesi ve Hasar Tespiti. Bartın Orman Fakültesi Dergisi, 23(1): 172-181. DOI: https://doi.org/10.24011/barofd.837507 
Polat N, Önal M, Ernst F B, Şenol H İ, Memduhoğlu A, Mutlu S, Mutlu S İ, Budan M A, Turgut M, Kara H (2020). Harran Ören Yeri Arkeolojik Kazı Alanınındın Çıkarılan Bazı Küçük Arkeolojik Buluntuların Fotogrametrik Olarak 3B Modellenmesi. Türkiye Fotogrametri Dergisi, 2(2), 55-59.

Sarı B, Hamal S N G \& Ulvi A (2020). Documentation of Complex Structure Using Unmanned Aerial Vehicle (UAV) Photogrammetry Method and Terrestrial Laser Scanner (TLS). Türkiye Lidar Dergisi, 2(2), 48-54.

Şenol H I, Erdogan S, Onal M, Ulukavak M, Memduhoglu, A, Mutlu S \& Yilmaz M (2017). 3D Modeling of a Bazaar in Ancient Harran City Using Laser Scanning Technique. International Archives of The Photogrammetry, Remote Sensing \& Spatial Information Sciences, 42.

Şenol H İ \& Kaya Y (2019). İnternet Tabanlı Veri Kullanımıyla Yerleşim Alanlarının Modellenmesi: Çiftlikköy Kampüsü Örneği. Türkiye Fotogrametri Dergisi, 1(1), 11-16.

Şenol H İ, Memduhoglu A \& Ulukavak M (2020). Multi instrumental documentation and 3D modelling of an archaeological site: a case study in Kizilkoyun Necropolis Area. Dicle Üniversitesi Mühendislik Fakültesi Mühendislik Dergisi, 11(3), 1241-1250.

Tapan K S, Bölme M \& Eker O, (2015). Görüntülerden Sınıflandırma Yöntemlerini Kullanarak Detayların Otomatik Olarak Belirlenmesi: Renkli Kızılötesi Hava Fotoğraflarından Ormanlı Alanlarda Yolların Belirlenmesi İçin Bir Sinıflandırma Uygulaması. TUFUAB VIII. Teknik Sempozyumu 21-23 Mayıs 2015 / Konya

Taşdemir Ş, Ürkmez A, Yakar M \& İnal Ş (2009). Sayısal görüntü analiz işleminde kamera kalibrasyon parametrelerinin belirlenmesi. 5. Uluslararası İleri Teknolojiler Sempozyumu, 13-15 Mayıs.
Ulukavak M, Memduhoğlu A, Şenol H İ \& Polat N (2019). The use of UAV and photogrammetry in digital documentation. Mersin Photogrammetry Journal, 1(1), 17-22.

Ulvi A, \& Toprak A S (2016). Investigation of threedimensional modelling availability taken photograph of the unmanned aerial vehicle; sample of kanlidivane church. International Journal of Engineering and Geosciences, 1(1), 1-7.

Ulvi A (2020). Importance of Unmanned Aerial Vehicles (UAVs) in the Documentation of Cultural Heritage. Turkish Journal of Engineering, 4(3), 104-112.

Yakar M \& Dogan Y (2018). 3d Reconstruction Of Residential Areas with SfM Photogrammetry. In Conference of the Arabian Journal of Geosciences ( $p p$. 73-75). Springer, Cham.

Yiğit A Y \& Kaya Y (2020). Sentinel-2A uydu verileri kullanılarak sel alanlarının incelenmesi: Düzce örneği. Türkiye Uzaktan Algılama Dergisi, 2(1), 1-9.

Yiğit A Y \& Uysal M (2019). Nesne Tabanlı Sinıflandırma Yaklaşımı Kullanılarak Yolların Tespiti, Türkiye Fotogrametri Dergisi, 2019; 1(1);01-06

Yiğit A Y \& Uysal M (2020). Automatic Road Detection from Orthophoto Images. Mersin Photogrammetry Journal, 2(1), 10-17.

Yiğit A Y, Orhan 0 \& Ulvi A (2020). Investigation of The Rainwater Harvesting Potential at The Mersin University, Turkey. Mersin Photogrammetry Journal, 2(2), 64-75.

Yilmaz H M, Yakar M, Mutluoglu 0, Kavurmaci M M \& Yurt $\mathrm{K}$ (2012). Monitoring of soil erosion in Cappadocia region (Selime-Aksaray-Turkey). Environmental Earth Sciences, 66(1), 75-81. 